\title{
BUSSEK, Holger, DAMKEN, Martin, MÜLLER, Thomas, REGENBRECHT, Martin, Deutsche Verfassungen
}

\section{Nicolas Le Moigne}

\section{(2) OpenEdition \\ Journals}

Édition électronique

URL : http://journals.openedition.org/ifha/683

DOI : $10.4000 /$ ifha.683

ISSN : 2198-8943

Éditeur

IFRA - Institut franco-allemand (sciences historiques et sociales)

Référence électronique

Nicolas Le Moigne, «BUSSEK, Holger, DAMKEN, Martin, MÜLLER, Thomas, REGENBRECHT, Martin, Deutsche Verfassungen », Revue de l'IFHA [En ligne], Date de recension, mis en ligne le 01 janvier 2006, consulté le 22 septembre 2020. URL : http://journals.openedition.org/ifha/683 ; DOI : https://doi.org/ 10.4000/ifha.683

Ce document a été généré automatiquement le 22 septembre 2020.

(CIFHA 


\title{
BUSSEK, Holger, DAMKEN, Martin, MÜLLER, Thomas, REGENBRECHT, Martin, Deutsche Verfassungen
}

\author{
Nicolas Le Moigne
}

1 Le CD-ROM est un instrument de plus en plus précieux, dans la mesure où il permet de collationner un nombre impressionnant de sources dans un objet peu encombrant et d'utilisation pratique, doté de moteurs de recherche permettant un accès ciblé aux documents. Il apparaît de plus en plus comme le moyen le plus adapté aux éditions systématiques, comme en témoignent ces deux recueils, l'un diachronique (les constitutions allemandes depuis le début du XIXe s.), l'autre synchronique (les constitutions européennes pendant la période révolutionnaire et napoléonienne).

Les éditeurs des Quellen zur europäischen Verfassungsgeschichte ont fait le choix d'une double édition, électronique et sur papier, puisque les textes rassemblés seront édités par la suite dans un Handbuch der europäischen Verfassungsgeschichte im 19. Jahrhundert. L'ensemble de l'entreprise est soutenu financièrement par la FriedrichEbert-Stiftung. Le premier volet de ce projet, qui devrait en comporter quatre, rassemble 1115 documents, répartis entre la fin du XVIIIe s. et 1815. Les éditeurs ont choisi de s'en tenir à l'Europe, en excluant délibérément les textes constitutionnels américains, pourtant déterminants à cette période. Le cadre chronologique est souple : dans le cas britannique, par exemple, les grands textes « constitutionnels » antérieurs à la période et toujours en vigueur sont eux aussi reproduits (Grande Charte, Habeas Corpus, Bill of Rights, etc.). La mise en série des textes permet de mettre en évidence les modèles et les emprunts qui se diffusent en Europe lors de cette première vague de constitutions écrites - voire les copies hâtives, comme en témoignent les constitutions des Républiques-sœurs. À l'occasion, on trébuche sur un texte inattendu, comme la constitution de la République des Îles Ioniennes, qui reprend les structures du régime oligarchique de la période vénitienne en lui donnant formellement les apparences d'un parlementarisme à la britannique. Les textes sont reproduits en langue originale, avec une traduction ou du moins un résumé en langue allemande, à l'exception des textes en 
anglais et en français - le CD-ROM est donc tout à fait utilisable par un nongermanophone. Le moteur de recherche a fait l'objet d'un soin particulier. Outre les fonctions classiques - recherche par pays, par date - il offre également un menu thématique autour de 134 mots-clefs (paysannerie, armée, société, parlement, etc.), qui permet de balayer tous les textes en fonction d'une question ciblée. Les éditeurs ont en effet voulu éviter l'impasse de la collection destinée exclusivement aux historiens du droit, et rendre les textes disponibles pour des recherches d'histoire politique, sociale ou économique. Le pari est pleinement réussi.

Le CD-ROM Deutsche Verfassungen est quant à lui une entreprise moins originale, dans la mesure où il existe déjà plusieurs recueils de ce type sur papier, correspondants allemands du recueil Garnier-Flammarion des constitutions françaises. Il s'agit essentiellement ici d'un changement de support, dans un but pratique. Au total, près de cent textes sont préséntés. La constitution américaine et les constitutions françaises de 1791 et 1793, ainsi que la Charte de 1814, ont été intégrées (en version originale et en traduction allemande) eu égard à leur rôle de " précurseurs et modèles " (Vorläufer und Vorbilder). L'éclatement confédéral jusqu'en 1871, le pluralisme fédéral qui lui a succédé, ainsi que les multiples changements de régime expliquent la passionnante diversité des types de régime reflétée par ces lois fondamentales : monarchie libérale (Bade) ou féodale (Mecklembourg avant 1918), république oligarchique (villes hanséatiques), république présidentielle (Weimar), parlementarisme (Bonn), démocratie populaire (RDA), etc. Les constitutions de Länder sont aussi présentées pour la période postérieure à l'unité.

4 Les deux recueils mettent néanmoins en lumière les lacunes de l'histoire constitutionnelle, qui tend à gommer les formes de pouvoir qui méconnaissent la constitution écrite de facture américaine ou française. Dans le panorama européen de BRANDT, KIRSCH et SCHLEGELMILCH, chaque pays n'apparaît qu'à partir du moment où il se dote d'une constitution, sans que le contexte d'édiction de celle-ci soit précisé, ni la nature du système politique qui l'a précédée. De même, le recueil Deutsche Verfassungen laisse une place de choix à la constitution fédérale de 1848, qui n'est jamais entrée en vigueur, alors que le Reich national-socialiste n'est présent qu'à travers les textes de démantèlement de la constitution de Weimar en 1933-34, puisqu'il ne s'est jamais donné par la suite de loi fondamentale. Les matériaux rassemblés dans ces deux éditions doivent donc être pris pour ce qu'ils sont (un ensemble de textes d'un type spécifique) et appellent à être systématiquement complétés par d'autres documents d'histoire politique.

Nicolas LE MOIGNE (Lycée Michel-de-Montaigne, Mulhouse) 